\title{
评 述水库大坝安全与风险专题
}

\section{大坝风险评估与管理关键技术研究进展}

\author{
盛金保 ${ }^{1,2,3}$, 厉丹丹 ${ }^{1,2 *}$, 蔡菖 ${ }^{1,2}$, 彭雪辉 ${ }^{1,2}$ \\ 1. 南京水利科学研究院, 南京 210029 ; \\ 2. 水利部大坝安全管理中心, 南京 210029 ; \\ 3. 水利部土石坝破坏机理与防控技术重点实验室, 南京 210029 \\ *E-mail:wizertize@foxmail.com
}

收稿日期: 2018-08-21; 接受日期: 2018-10-08; 网络版发表日期: 2018-10-11

国家重点研发计划项目(编号: 2018YFC0407106, 2016YFC0401603)、国家自然科学基金项目(批准号: 51679151)、中央级公益性科研院所基 本科研业务费专项资金项目(批准号: Y717012)和水利部公益性行业科研专项经费项目(批准号: 201501033)资助

\begin{abstract}
摘要 大坝风险客观存在, 对大坝风险进行评估和管理, 事关工程安全和公共安全. 本文基于中国的溃坝概率统 计分析，简要回顾了大坝风险评估和管理技术发展过程，阐述了大坝风险管理内涵，对溃坝模式和溃坝路径识 别、溃坝概率与溃坝后果计算、人因可靠性、梯级水库群风险评估与控制、大坝风险标准和风险决策等涉及大 坝风险评估与风险管理的关键技术进行了综述，对风险排序和决策、风险预警及应急预案、降等报废、大坝安 全年度报告、运行维护与监测手册等风险管理实用技术和工具在中国大坝安全行业管理的应用现状进行了总 结, 展望了大坝风险评估与管理技术未来的研究方向, 以期引起全行业更深入的探讨, 促进中国大坝尽快由“工程 安全管理”向“风险管理”的转变.
\end{abstract}

关键词大坝, 人因可靠性, 风险评估, 凤险管理

\section{1 引言}

大坝在发挥各种功能的同时，也存在无法回避的

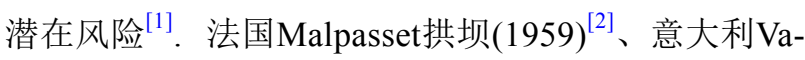
jont拱坝 (1963) $)^{[3]}$ 、美国Teton坝 (1976) ${ }^{[4]}$ 和Oroville坝 $(2017)^{[5]}$ 、俄罗斯萨扬舒申斯克电站 $(2009)^{[6]}$ ，以及中 国板桥水库 $(1975)^{[7]}$ 、沟后水库 $(1993)^{[8]}$ 等大量造成严 重后果的国内外溃坝或出险事故案例警示我们，关注 大坝风险并对其进行管理，不仅是关系工程安全，更 是关系公共安全的重大课题.

大坝风险是对其负面影响可能性和严重性的度
量, 溃坝风险是溃坝概率与溃坝后果的组合. 前者取决 于大坝工程本质安全，后者与下游人口、基础设施分 布及社会经济发展程度有关.

大坝风险管理是一种以风险控制为核心的全过程 动态管理. 通过采用管理、控制风险的一整套政策和 程序，对风险进行监控、分析、评估和处理. 大坝风 险管理包括两个重要理念：一是大坝风险始终存在, 无法完全回避；二是需要承受适度风险，“适度风险” 指社会和公众可以接受的风险，可以通过采取适当措 施预防和控制实现. 因此, 在大坝风险管理理念中, 一 座“安全”的大坝, 首先是其风险能被接受, 其次才是完

引用格式: 盛金保, 厉丹丹, 蔡莳, 等. 大坝风险评估与管理关键技术研究进展. 中国科学: 技术科学, 2018, 48: 1057-1067

Sheng J B, Li D D, Cai Q, et al. Research progress and its practice of key techniques for dam risk assessment and management (in Chinese). Sci Sin Tech, 2018, 48: 1057-1067, doi: 10.1360/N092018-00277 
成其预定功能 ${ }^{[9]}$.

20世纪50 80年代是中国溃坝高发期，1954 1982 年共溃坝 3115 座, 年均 107 座, 平均年溃坝率 $1.23 \% ; 20$ 世纪 80 年代后, 通过加强管理, 中国溃坝数量显著减 少, 1983 1999年溃坝332座, 年均19.5座, 平均年溃坝 率 $0.23 \%$. 近 20 年来, 大坝风险评估和管理技术在中国 得到快速发展, 并在大坝安全管理实践中得到初步应 用, 取得良好效果, 溃坝概率大幅度降低(图 1), 2000 2014年溃坝73座, 年均4.9座, 平均年溃坝率进一 步降至 $0.05 \%$ 。 以下 $^{[10]}$.

\section{2 大坝风险评估和管理技术发展过程}

大坝风险理念始于1976年美国Teton坝和后来的 Taccoa Fans坝相继失事. 1982年美国陆军工程师团 (USACE) 提出了用相对风险指数来判别大坝风险概 念, 美国唇务局(USBR)推荐使用现场评分法来衡量水 库大坝的风险, 葡萄牙工程师考虑了环境、工程结构 和溃坝损失三个方面 11 个风险因素, 综合成为风险指 数, 评价工程的风险. 第一阶段的特征是选择某些影 响大坝和下游安全的因素, 根据工程师的经验, 通过 赋值的方法来评价大坝风险.

20 世纪90年代, 是大坝风险概念和体系形成的阶 段, 以加拿大、美国、澳大利亚为代表, 建立了以风 险分析技术为基础的大坝安全评价方法, 制定了一系 列风险评价的有关法规和指南, 形成了风险管理的基 本框架. 加拿大标准协会1991年发布了《风险分析必 要条件和指南》(CAN/CSA-Q634-91)；1994年澳大利 亚大坝委员会(ANCOLD)颁布了《ANCOLD风险评估 指南》, 为大坝安全评估的应用提供了概念性基础. 1995年澳大利亚和新西兰标准局发布了《风险管理》
标准, 奠定了风险、风险分析和风险管理的基础. 加拿 大 BC Hydro负责管理不列颠哥伦比亚省(British Columbia)内43座水库大坝的安全. BC Hydro于1991 年把风险分析方法引入大坝安全评估中, 荷兰、美 国、英国、南非等国家都对大坝风险的各个方面进行 了深入系统的研究. 1999年欧盟支持芬兰进行了包括 大坝溃决的危险、公众在大坝溃决事件中的反应、人 和建筑物在溃坝洪水中的稳定性、生命损失和应急预 案等问题的研究. 该阶段的主要特征是建立了完整的 法规指南体系, 形成了一套系统的、完整的分析方法 和技术、评价和管理体系. 风险分析和管理把水库大 坝作为一个系统，对组成系统的各部分的安全性，利 用事件树、故障树技术，分析破坏概率; 对下游的人 员、经济、社会、环境损失做出评价; 并建立可接受 风险和可容忍风险标准, 对大坝风险做出判断.

2000年在北京举办的第20届国际大坝会议第一次 将大坝风险分析作为国际大坝会议议题, 标志着大坝 工程方面风险分析已经发展成为体系完整的决策工 具. 2000 年 10 月, 在芬兰举办了有 15 国代表参加的大坝 Rescue工程研讨会, 在下游影响分析方面, 如生命损失 的估算、水库下游村镇的风险管理、应急预案、溃坝 洪水分析平台等问题上做了详细研究. 2002年, 在欧盟 第五框架计划中，欧盟组织挪威、英国、荷兰等国家 对大坝溃决和洪水演进进行了实验室和现场试验研 究, 其中在挪威进行了 6 次大坝溃决的现场试验, 在英 国进行了 23组室内溃坝模型试验, 在西班牙进行了小 型溃坝模型试验，并对溃坝洪水及其不确定性进行了 系统研究. 2003年10月澳大利亚大坝委员会 (ANCOLD)正式发布《风险评估指南》, 同年国际大坝委 员会发布了《大坝安全管理中的风险评估》通告. 这 个文件由 5 位来自澳大利亚、加拿大、美国和荷兰的

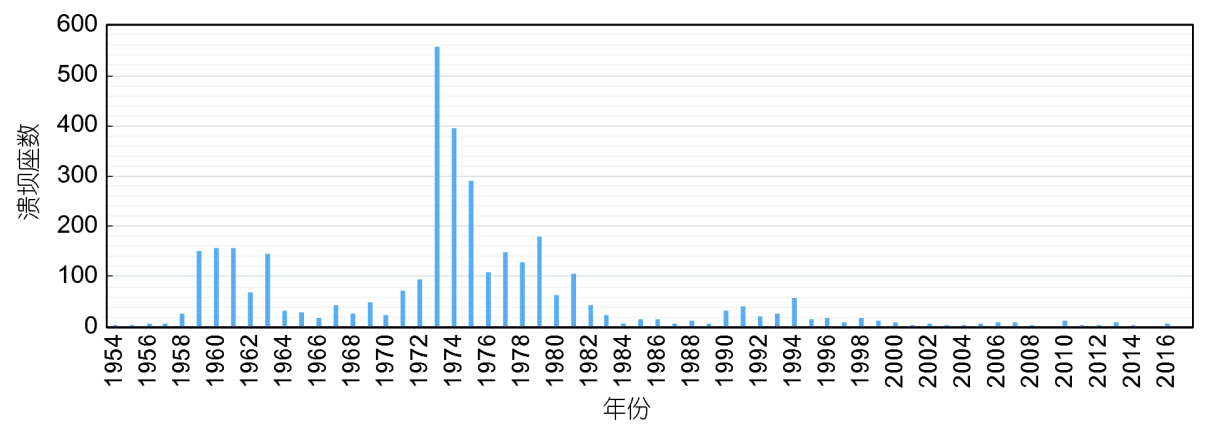

图 1 (网络版彩图)历年溃坝数量分布图 
风险评价和管理专家起草，标志着风险概念已经被世 界接受, 风险评价和管理技术将在大坝安全管理中起 到越来越重要的作用. 在2006年6月西班牙召开的第 22届国际大坝会议上, 有关大坝风险分析与风险管理 的研究成果仍为全世界坝工界关注的热点问题.

目前, 在加拿大、澳大利亚等国家, 大坝风险管理 已进入实用阶段, 风险管理模式替代了传统的工程安 全管理模式, 在大坝设计和安全评价(复核)中, 采用按 风险划分工程等别和确定设计标准; 重视对大坝安全 的持续监控, 发现安全隐患及时进行处理; 重视突发 事件应急管理, 每一座大坝都需要编制应急预案.

中国从 21 世纪初开始大坝风险评估和管理研究及 应用, 并取得一系列符合国情的成果 ${ }^{[11,12]}$. 系统挖掘了 溃坝生命损失影响因素的主要特征, 揭示了溃坝生命 损失规律, 构建了适合中国实际情况的溃坝生命损失 率模型 ${ }^{[13,14]}$; 建立了基于风险的大坝安全评价方法的 体系框架, 提出了溃坝模式与溃坝概率分析计算、溃 坝后果评估与综合评价等一系列方法和模型 ${ }^{[15 ~ 17]}$; 揭 示了经济社会发展水平与政府、公众风险承受能力的 内在关系 ${ }^{[18,19]}$, 以及溃坝生命风险地域性、时变性和 社会性特点, 建立了大坝风险综合评价模型 ${ }^{[20,21]}$, 提 出了中国大坝生命、经济、社会和环境风险标准 ${ }^{[22]}$; 在水库大坝风险控制非工程措施研究方面, 提出了应 急预案可行性和有效性评价方法 ${ }^{[23,24]}$, 明晰了水库降 等报废对生态环境影响, 建议了水库降等报废后的环 境生态修复对策 ${ }^{[25]}$, 编制了 《水库大坝安全管理应急 预案编制导则》 ${ }^{[26]}$ 和《水库降等与报废标准》 ${ }^{[27]}$, 并 在实际工程中应用.

\section{3 大坝风险评估与管理关键技术研究现状}

\section{1 溃坝模式和溃坝路径识别}

破坏模式和溃坝路径识别是分析在外部荷载作用 下, 大坝各组成部分可能出现的破坏形式及是否会发 展成溃坝事件, 最终形成从“荷载-建筑物-破坏-溃坝” 的途径, 是大坝风险分析的基础 ${ }^{[28]}$.

李雷等人 ${ }^{[29]}$ 在系统分析历史溃坝资料基础上, 归 纳了土石坝 5 类主要溃坝模式, 即洪水漫顶、滑坡、 渗透破坏、地震破坏、人为破坏(战争、恐怖袭击), 以及 24 种可能的溃坝路径; 傅忠友和张士辰 ${ }^{\left[{ }^{[0]}\right.}$ 基于重 力坝的特点和溃坝案例, 认为导致重力坝溃决的主要
影响因素为洪水漫顶、基础缺陷和战争, 归纳了重力 坝3类主要溃决模式和 11 条溃坝路径.

蔡荨 $^{[31}$ 提出了基于模糊贴近度的溃坝模式识别 方法和溃坝路径挖掘层次分析方法, 即通过分析与 标准破坏模式的相似程度来判断何种溃坝模式最可能 发生. 设 $X \neq \varphi, \quad \xi \subseteq F(X)$, 且 $\xi$ 是 $X$ 上的正规模糊集 的全体. $N_{1}, N_{2}: \xi \times \xi \rightarrow[0,1]$, 对于任意模糊集 $A, B \in F(X)$, 有如下贴近度函数:

$$
\begin{aligned}
& N_{1}(B, A)=\underset{x \in X}{\vee}\left[\mu_{B}(x) \wedge \mu_{A}(x)\right], \\
& N_{2}(B, A)=\underset{x \in X}{\vee}\left[\mu_{B}(x) T \mu_{A}(x)\right],
\end{aligned}
$$

式中, $T$ 为 $[0,1]$ 上的 $T$-模; $\wedge, \vee$ 分别为取大和取小运 算符.

采用极值法取贴近度最高的标准破坏模式为计算 结果, 即:

$\bigwedge_{j=1}^{m} N\left(B_{j}, A_{k j}\right)=\bigvee_{i=1}^{4}\left[\bigwedge_{j=1}^{m} N\left(B_{j}, A_{i j}\right)\right]$.

对各个破坏模式先给定权重, 权重向量可表示为 $W=\left(w_{1}, w_{2}, \ldots, w_{n}\right)^{\mathrm{T}}$, 将权重向量与贴近度相乘获得最 贴近的破坏模式, 即为溃坝模式:

$$
\sum_{j=1}^{m} w_{j} N\left(B_{j}, A_{k j}\right)=\bigvee_{i=1}^{4}\left[\sum_{j=1}^{m} w_{j} N\left(B_{j}, A_{k j}\right)\right] .
$$

随着洪水预报、突发事件预测预警、工程抢险等 水平的提高, 人工干预对溃坝模式和溃坝路经发展的 影响越来越显著, 通过人工干预中止溃坝事故发生的 成功率越来越高, 在今后的溃坝模式和溃坝路径识别 方法研究中, 应考虑人工干预和人因可靠性的影响.

\section{2 溃坝概率计算}

风险理念刚引入到大坝安全领域时，国内外学者 尝试通过理论方法(如可靠度法) ${ }^{[32]}$ 定量计算溃坝概率. 但由于环境、人因、模型、参数等各种不确定性, 采 用理论方法计算溃坝概率的困难很大, 结果并不“可 靠”. 因此, 人们转而采用基于专家经验的定性和半定 量方法来计算溃坝概率, 如事件树法 ${ }^{[33]}$, 由专家根据 经验定量确定溃坝路径上各个环节发生的概率, 把专 家对某一事件可能出现的定性判断转化为定量概率. 显然, 如此计算得到的“溃坝概率”并不是真实的溃坝 概率, 仅可作为水库调度运用、维修养护、除险加 
固、降等报废等决策依据. 为尽量减少人为因素的影 响，在对群坝开展风险评估时，应尽量由同一批经验 相当的专家完成. 未来, 需要在加强各种不确定性研 究的基础上, 进一步深化溃坝概率定量计算方法研究.

如何协调衔接好大坝风险评价体系与现行大坝安 全评价体系的关系，建立溃坝概率与大坝结构安全系 数之间的转换关系，是另一个需要考虑的关键技术 问题.

根据可靠度理论 ${ }^{[34]}$, 可以建立如下大坝工作状态 的功能函数:

$Z=g\left(X_{1}, X_{2}, \ldots, X_{n}\right)=g(R, S)=R-S$,

式中, $Z$ 为大坝功能函数; $X_{1}, X_{2}, \ldots, X_{n}$ 为影响大坝安全 的随机因子; $R$ 为抗力随机因子; $S$ 为荷载效应随机 因子.

溃坝概率 $P$ 按下式计算:

$$
\begin{aligned}
P_{f} & =P(Z<0)=P(R<S) \\
& =\iint_{Z<0} \cdots \int f_{X}\left(x_{1}, x_{2}, \cdots, x_{n}\right) \mathrm{d} x_{1} \mathrm{~d} x_{2} \cdots \mathrm{d} x_{n},
\end{aligned}
$$

式中, $f_{X}\left(x_{1}, x_{2}, \ldots, x_{n}\right)$ 为随机因子 $X_{1}, X_{2}, \ldots, X_{n}$ 的概率密 度函数.

大坝安全可靠度指标 $\beta$ 按下式计算:

$\beta=\frac{\mu_{R}-\mu_{S}}{\sqrt{\sigma_{R}^{2}+\sigma_{S}^{2}}}$,

式中, $\mu_{R}$ 和 $\mu_{S}$ 分别为 $R$ 和 $S$ 的均值; $\sigma_{R}$ 和 $\sigma_{S}$ 分别为 $R$ 和 $S$ 的标准差.

溃坝概率 $P_{f}$ 与可靠指标 $\beta$ 之间存在如下关系:

$P_{f}=1-\Phi(\beta)=\Phi(-\beta)$.

当 $R$ 和 $S$ 均为正态分布时, 可靠指标 $\beta$ 与结构安全 系数 $K$ 存在如下关系:

$\beta=\frac{K-1}{\sqrt{K^{2} V_{R}^{2}+V_{S}^{2}}}$,

式中, $V_{R}$ 和 $V_{S}$ 分别为 $R$ 和 $S$ 的变异系数.

由上述可见，通过可靠度理论计算工程可靠度的 方法较为成熟，可靠度指标与失效概率的关系在理论 计算上较为清晰，但受制于工程材料样本不够、不同 工程有很强的变异性等因素，获得可靠的工程失效概 率计算参数十分困难. 因此, 通过可靠度理论定量计 算溃坝概率目前在实际操作层面上还存在很大困难,
现阶段还难以建立溃坝概率与大坝结构安全系数之间 的转换关系, 需要进一步加强相关研究.

\section{3 溃坝后果估算}

溃坝后果包括生命损失、经济损失和社会与环境 影响, 其估算首先需要进行溃坝洪水及其演进分析, 确 定溃坝洪水淹没范围 ${ }^{[35,36]}$, 目前国内外相关研究成果 非常丰富，如用于溃口洪水分析的BREACH模型 ${ }^{[37]}$ 、 李雷模型 ${ }^{[29]}$ 、陈生水模型 ${ }^{[38]}, \mathrm{BREACH}$ 模拟的溃口流 量过程见图2.

用于溃坝洪水演进分析有MIKE ${ }^{[39]}, \mathrm{HECRAS}^{[40]}$, $\mathrm{DAMBRK}^{[41]}, \mathrm{FLADWAV}^{[42]}$ 等水动力计算软件. 王晓 航等人 ${ }^{[35]}$ 提出将MIKE与 GIS技术结合的洪水演进分 析方法, 可获得直观的洪水要素分布情况, 供风险人口 应急转移决策使用(图3).

需要注意的是, 溃坝模式与坝型密切相关, 如重力 坝、拱坝溃坝形式多为瞬溃，应急反应时间相对较短; 而土石坝多为逐渐溃决, 有相对较长的预警和应急调 度时间. 今后仍需根据溃坝试验成果 ${ }^{[43,44]}$ 和实际溃坝 洪水资料 ${ }^{[45,46]}$, 针对不同坝型对溃坝模型进行修正完 善, 并加强具有自主知识产权的洪水演进分析软件 研发.

在溃坝洪水淹没范围确定后，即可估算溃坝后果. 在加拿大 ${ }^{[47]}$ 、美国 ${ }^{[48]}$ 、澳大利亚 ${ }^{[49]}$ 等国家, 在溃坝风 险研究的初期, 因经济损失估算相对简单, 故将生命损 失折算成金钱，以经济损失来度量总的溃坝后果. 后 来, 由于认为人的生命价值无法用金钱衡量, 故在估 算溃坝后果时，主要考虑生命损失，甚至近似以风险 人口代替生命损失. 用于溃坝生命损失估算的方法主 要有美国的B\&G法 ${ }^{[50]}$ 、Dekay \& McClelland法(D\&M 法 $)^{[51]}$ 、Graham 法 ${ }^{[52]}$ 以及加拿大的Assaf法 ${ }^{[53]}$, 其中

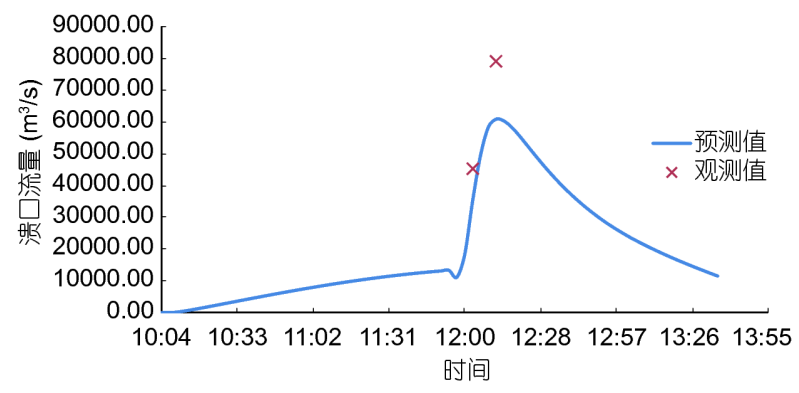

图 2 (网络版彩图)BREACH模拟Teton坝管涌溃坝流量 过程 


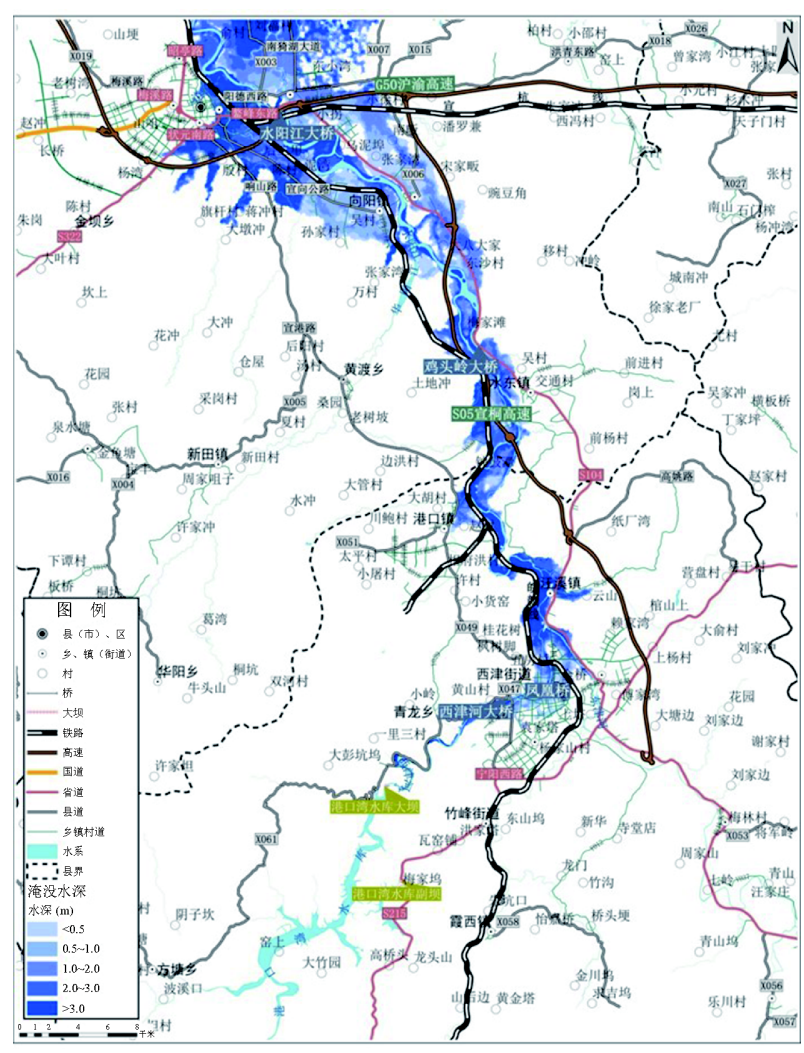

图 3 (网络版彩图)基于MIKE21与GIS技术的溃坝洪水演 进分析

B\&G法考虑的影响因素少，过于简单; Assaf法对风险 人口主观能动性及其和溃坝洪水的互动性研究还不够 深入, 且迭代计算过程过于繁琐, 很少使用.

由于国情不同，中国目前普遍分别估算溃坝生命 损失、经济损失和社会与环境影响. 李雷、周克发基 于中国历史溃坝生命损失数据，提出了李-周评价模 型 ${ }^{[29]}$, 对Graham法给出的风险人口死亡率推荐表进行 了修正，取得了较好效果; 盛金保和彭学辉 ${ }^{[54]}$ 建立了 溃坝社会与环境影响评价指标体系，定义了溃坝社会 与环境影响指数, 用以评判溃坝社会与环境影响严重 程度. 李雷等人 ${ }^{[55]}$ 还研究提出了如下溃坝后果综合评 价函数:

$L=\sum_{1}^{3} S_{i} F_{i}=S_{1} F_{1}+S_{2} F_{2}+S_{3} F_{3}$,

式中, $S_{1}, S_{2}, S_{3}$ 分别为生命损失、经济损失和社会与环 境影响的权重系数; $F_{1}, F_{2}, F_{3}$ 分别是生命损失、经济 损失和社会与环境影响的严重程度系数.

影响溃坝后果特别是生命损失的因素众多且存在
很大的不确定性 ${ }^{[56]}$, 例如, 溃坝生命损失除受风险人 口数量、溃坝洪水严重性、溃坝洪水发生时间、警报 时间、风险人口对溃坝洪水严重性的理解程度等主要 因素外, 还与风险人口的年龄、性别、健康状态、主 观选择以及居住环境、逃生路径、应急救援能力等因 素有关, 很难一一考虑周全 ${ }^{[57 ~ 61]}$. 未来还需要进一步 加强溃坝后果估算方法研究.

\section{4 人因可靠性}

早期溃坝机理和原因分析主要聚焦于坝体结果自 身的物理力学特性, 以及洪水等环境因素和质量缺陷 等工程因素. 随着技术进步和应急管理水平提高, 汛 期高水位条件下漫顶、渗漏、结构失稳等导致溃坝的 比例显著下降，非汛期人为因素触发的溃坝事故比例 反而相对上升 ${ }^{[62]}$. 2016年美国大坝安全年会提出“大 坝溃决和事故都可归结于人的原因”.

科学认知溃坝事故中人因失误作用机制和影响贡 献程度, 准确掌握人因失误规律, 已经成为进一步提升 大坝安全管理能力和避免溃坝事故的现实需求. 近年 来, 溃坝风险评估中的人因可靠性研究开始受到重视.

盛金保等人 ${ }^{[63]}$ 通过对多座病险水库除险加固项 目溃坝过程的调查分析, 揭示了病险水库除险加固项 目溃坝的主要原因是人为因素, 并定性归纳了人因失 误模式.

$\mathrm{Li}$ 等人 ${ }^{[64]}$ 通过对中国 3500 余座溃坝事故资料的统 计分析, 初步揭示了溃坝事故中导致人为失误的主要 影响因素为责任心、经验、风险意识、督查力度等, 并应用人为因素分析与分类系统(HFACS)法, 以人、 技术、组织、环境作为准则层, 构建了溃坝事故人因 失误影响指标体系(图4)及如下基于贝叶斯网络的大 坝人因可靠性模型:

$P\left(Y \mid X_{1}, X_{2}, \ldots, X_{n}\right)=\frac{\sum_{i=1}^{n} f_{i} w_{i}}{\sum_{i=1}^{n} w_{i}}$,

式中, $P$ 为人因失误概率; $Y$ 为人因失误模型功能函数; $X_{i}$ 为人因失误影响指标; $f_{i}$ 为影响指标状态概率值; $w_{i}$ 为影响指标权重; $n$ 为人因失误影响指标数量.

该模型已成功应用于洪泽湖堤坝工程人因可靠性 分析, 建立了洪泽湖堤抢险干预中人的可靠性模型, 计 算分析了抢险干预中的人因失误概率. 


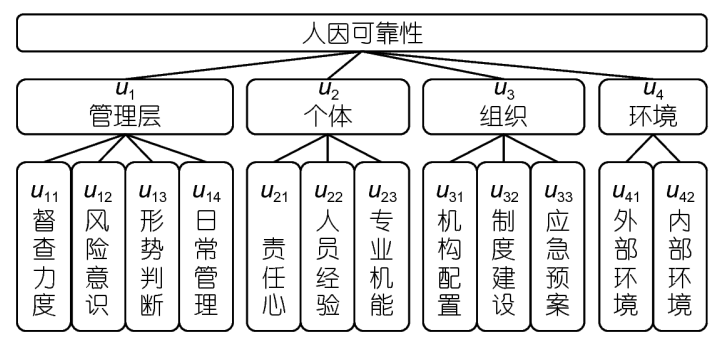

图 4 溃坝事故人因失误影响指标体系

目前，溃坝事故中的人因失误机理尚未得到科学 认知，溃坝事故中隐含了哪些关键人因环节和因子、 人因元素和概念如何客观表述、人因失误概率如何定 量计算、人因失误模式及对溃坝的“贡献程度”如何度 量等问题均未完全解决, 需要进一步深入研究.

\section{5 梯级水库群风险评估与控制}

相比单一梯级，流域梯级水库群风险具有传递和 叠加效应, 系统风险源识别更为复杂, 灾害链更长, 影 响范围更关 ${ }^{[65]}$. 在流域尺度下，一旦其中任何一座梯 级溃坝失事，则必然出现“多米诺骨牌效应”，导致难 以承受的后果 ${ }^{[66]}$. 因此, 流域梯级水库群系统风险评 估与控制成为近年来的重点研究方向之一.

\subsection{1 梯级水库群风险动态评估与控制方法}

周建平等人 ${ }^{[67]}$ 针对流域多源风险，以“叶斯网 络”理论为基础，初步构建了梯级水库群“规划-设计运行”全生命周期风险动态评估与控制方法(图5).
规划阶段重在主动规避风险. 基于统计信息和知 识经验，建立梯级水库群重大风险识别模型，提出流 域超标准洪水、强地震和溃坝洪水多源风险及其组合 作用下大坝失效概率计算方法，对识别的重大风险因 素，通过改变梯级布局来规避，难以规避则需要改变 梯级开发方式和控制工程规模，以降低后期风险管控 的难度.

设计阶段重在风险防范. 基于可靠度理论和多源 信息融合，提出地震液化、渗透破坏、泄水系统和生 命线公路失效概率计算方法，构建梯级水库风险分析 模型，评估采取规避措施后的剩余风险，通过调整枢 纽布置和建筑物设计, 将风险控制在一定水平内.

运行阶段重在风险预警。综合监测信息和数值仿 真反馈信息，实时评估梯级水库群的动态风险，对超 设计水平的风险及时发出预警信号，必要时启动应急 预案. 同时, 借助贝叶斯风险网络, 综合分析各种风险 源, 通过卷积积分修正设计阶段提出的风险预警指标.

\subsection{2 梯级水库群风险防控设计}

周建平等人 ${ }^{[68]}$ 从公共安全和工程安全的角度，提 出了公众可接受的梯级水库群风险标准, 即可接受风 险标准为失效概率 $10^{-6} \mathrm{a}^{-1}$, 可容忍风险标准为失效概 率 $10^{-5} \mathrm{a}^{-1}$ ．基于失效概率大小和后果严重程度，采用 风险矩阵建立了梯级水库群风险等级, 即极高( I )、 高(II)、中(III)、低(IV)四级, 并提出了相应的风险应 对策略和控制方案.

从流域系统风险防控角度，提出了“控制梯

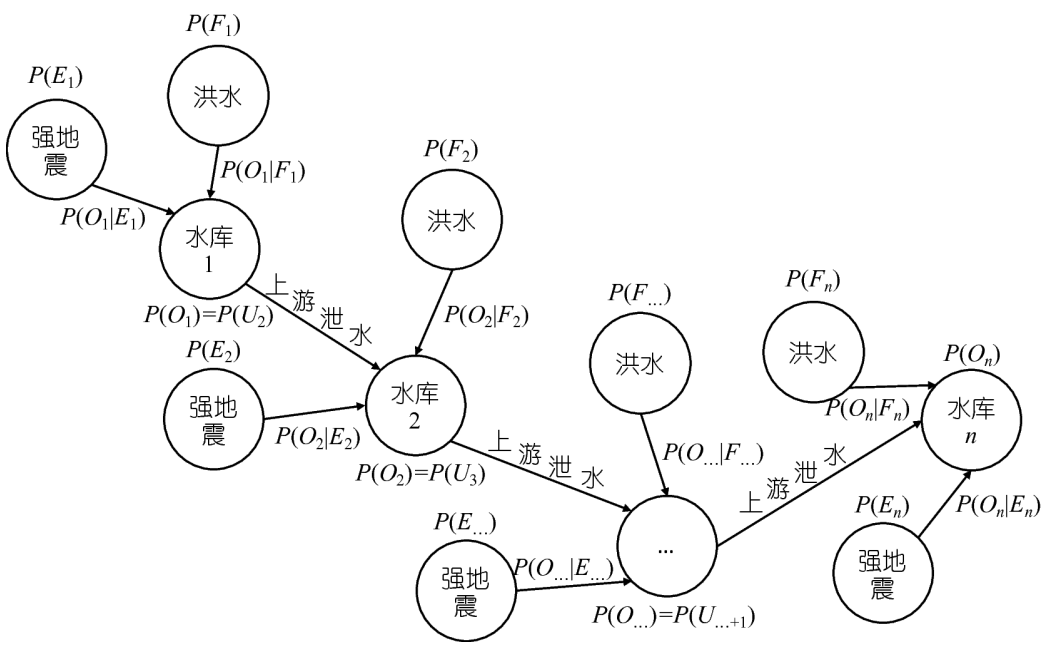

图 5 流域贝叶斯网络风险分析图 
级”、“一般梯级”和“薄弱梯级”概念，即具有足够的调 洪能力, 可截断、削弱流域系统风险传递, 但自身溃决 将导致流域产生灾难性后果的梯级为控制梯级, 其决 定流域的风险水平; 失效概率最大的为薄弱梯级, 是 触发流域系统风险的梯级; 其余为一般梯级. 与目前 工程等别分类系统有一定的对应关系，控制梯级对应 特等工程和大(1)型工程，一般梯级对应大(2)型工程, 薄弱梯级对应中小型工程.

综合考虑坝高、库容和溃坝后果严重性，提出了 “特等工程”、“特级建筑物”的分类分级标准. 定义坝 高 $200 \mathrm{~m}$ 以上、库容大于 10 亿 $\mathrm{m}^{3}$ 或溃坝可能导致下游 1 级大坝连溃的枢纽为特等工程, 特级建筑物的目标可 靠指标设为 $4.45 \sim 4.7$, 失效概率为 $1.0 \times 10^{-8}$ $5.0 \times 10^{-8} \mathrm{a}^{-1}$.

流域梯级风险的诱发、传导及演化机制极其复 杂, 现有研究成果和经验尚无法全面揭示, 上述梯级水 库群风险动态评估理论和方法尚有待实践检验和进一 步完善, 在现有安全标准基础上进一步提高特级建筑 物的目标可靠指标是否有效和经济合理，也需要进一 步研究探讨.

\section{6 大坝风险标准及风险决策}

大坝风险标准是风险评估和决策的依据，也是大 坝风险管理的目标，是依据大坝工程安全程度、溃坝 后果及承受能力进行评估后社会与公众可以接受的标 准，其涉及经济社会发展社会水平、风险意识、传统 文化背景、价值观、管理体制、保险制度等各个方 面，社会经济的发展与变化直接或间接影响风险管理 目标的确定. 合理的大坝风险标准可以达到协调工程 安全、下游安全及可持续发展的综合管理目标.

国内外一般均将风险划分为 4 级, 即I级, 极高风 险; II级, 高风险; III级, 中等风险; IV级, 低风险. 彭雪 辉等人 ${ }^{[22,69]}$ 、盛金保等人 ${ }^{[54]}$ 经研究后提出了中国大坝 风险定性和定量分级标准, 但尚未形成广泛共识, 也缺 少大量的实践应用和检验, 需要进一步深入研究和 应用.

大坝风险决策是通过与风险标准的比较, 评估风 险是否可接受、可容忍或不可接受. 若风险处于可接 受风险范围, 则无须处理; 若风险处于可容忍范围, 则 需要根据ALARP原则, 采用成本效益法或失衡法分析
确定风险是否需要处置; 若风险处于不可接受范围, 则 应采取措施进行处理. 常用的大坝风险处理措施包括 降低风险、转移风险、规避风险及保留风险.

\section{4 大坝风险管理}

尽管大坝风险评估与风险管理技术仍在发展过程 中, 但大坝风险理念已被广泛接受, 风险排序、应急预 案、降等报废、大坝安全年度报告、运行维护和监测 手册等风险管理实用技术和工具已在中国大坝安全行 业管理实践中得到广泛应用.

\section{1 大坝风险排序}

中国病险水库数量多, 除险加固经费短缺的矛盾 突出, 为此李雷等人 ${ }^{[70]}$ 提出按如下综合风险指数 $R$ 对 群坝进行排序, 以确保风险高的病险水库大坝优先得 到除险加固.

$R=P_{f} L$,

式中, $P_{f}$ 为溃坝概率; $L$ 溃坝后果综合评价函数, 见 式(10).

对单座大坝来说, 可对风险要素进行排序, 在资金 不足的情况下, 以确保主要风险要素得以优先处理. 大 坝风险要素排序可采用FMECA法(failure mode, effects and criticality analysis), 即破坏模式、后果和危害程度 分析法 ${ }^{[0]}$.

\section{2 风险预警及应急预案}

应急预案是避免或减少溃坝对下游生命、财产、 基础设施、生态环境造成灾难性后果而预先制定的紧 急行动方案, 是最重要的大坝风险管理工具. 应急预案 能否有效发挥作用, 关键能否提前对风险进行预警. 当 风险增大时按照规定的权限和程序发布预警，并启动 相应的应急响应. 预警级别由突发事件严重程度确定. 盛金保等人 ${ }^{[26]}$ 研究提出了4级预警级别及对应的应急 响应措施，张士辰等人 ${ }^{[71]}$ 提出了风险人口应急转移路 径优选机制及其简易评价方法, Cheng等人 ${ }^{[72]}$ 研究提 出了应急预案可行性、有效性评价技术. 目前大坝应 急管理仍存在许多待解决与完善的问题: 一是如何建 立科学有效的风险预警机制是一大难题; 二是高坝大 库一旦出险, 大量风险人口的撤离难以保障; 三是中 


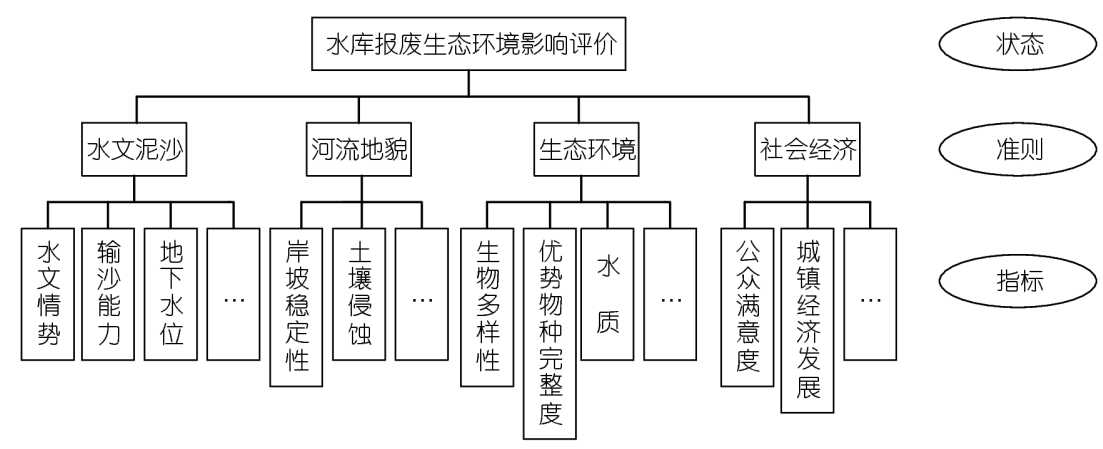

图 6 水库报废生态环境影响评价指标体系

国水库众多,特点各异, 如何建立统筹兼顾的应急管理 体系需要进一步深入研究.

\section{3 水库降等与报废}

当大坝风险不满足可接受风险标准，而风险处理 投入与取得的效益非常不相称时，可对大坝实施降等 或报废处理，从而回避风险 ${ }^{[73,74]}$. 李雷等人 ${ }^{[27]}$ 研究提 出了水库降等与报废标准，赵雪莹 ${ }^{[75]}$ 在水库报废生态 环境影响及其修复对策研究基础上，提出了水库报废 决策方法 ${ }^{[76]}$ (图6), 为水库降等与报废决策和善后处理 提供了科学依据.

\section{4 大坝安全年度报告}

大坝安全年度报告也是非常重要的大坝风险管理 工具，主要总结上一年度存在问题的整改情况与效果, 以及本年度内调度运用、巡视检查、安全监测、操作 测试、维修养护、突发事件应急等方面的工作成果与 经验, 并对闸门测试、安全监测等资料进行分析, 评价 年度内大坝安全状况与管理工作，提出必要的改进措 施建议，为下一年度养护修理计划制订、经费安排提 供科学依据，也是主管部门有效监管大坝安全与风险 的手段.

\section{5 运行维护与监测手册}

大坝运行维护与监测手册是规范大坝日常管理、调 度运行、安全监测、维修养护、应急管理等工作的制
度化、程序化、精细化的技术性文件，可以保证相关工 作的连贯性、一致性, 不受管理人员变更的影响, 从而 将人为失误风险降低至最低程度. 目前的运行维护与 监测手册编制还不规范, 需要尽快研究制订编制指南.

\section{5 结论与展望}

大坝风险管理以“工程风险”为核心，不仅关注工 程安全，同时关注下游公共安全，是更加科学合理的 现代大坝安全管理模式. 受各种不确定性影响, 大坝 风险评估与风险管理关键技术目前仍在发展过程中, 以基于专家经验的定性和半定量方法为主，通过理论 方法定量计算大坝溃决概率和溃坝后果的难度还很 大, 溃坝事故中人因失误尚未得到科学认知, 流域梯级 风险的诱发、激发、传导机制尚不明晰，尚无法建立 溃坝概率与大坝结构安全系数之间的转换关系，大坝 风险标准仍未形成共识，未来需要进一步深入相关 研究.

现阶段，风险排序、应急预案、大坝安全年度报 告、降等报废等风险管理实用技术和工具已在大坝安 全行业管理中得到初步应用，需要进一步开展溃坝风 险预警与应急管理体系以及水库报废决策方法和生态 修复技术等研究. 由于风险要素识别、溃坝模式与溃 坝路径分析、事件定性描述与发生概率之间的定量转 换都依赖于专家经验，当对群坝进行风险评估和决策 时，应由同一批专家完成，以尽量减少主观因素的 影响.

\section{参考文献}

1 李雷, 蔡跃波, 盛金保. 中国大坝安全与风险管理的现状及其战略思考. 岩土工程学报, 2008, 30: 1581-1587 
2 Valiani A, Caleffi V, Zanni A. Case study: Malpasset dam-break simulation using a two-dimensional finite volume method. J Hydraul Eng, 2002, 128: $460-472$

3 Paronuzzi P, Rigo E, Bolla A. Influence of filling-drawdown cycles of the Vajont reservoir on Mt. Toc slope stability. Geomorphology, 2013, 191: 75-93

4 Muhunthan B, Pillai S. Teton dam, USA: Uncovering the crucial aspect of its failure. Proc Inst Civil Eng-Civil Eng, 2008, 161: 35-40

5 Vahedifard F, AghaKouchak A, Ragno E, et al. Lessons from the Oroville dam. Science, 2017, 355: 1139-1140

6 贾金生, 徐洪泉, 李铁友, 等. 通过萨扬-舒申斯克水电站事故原因分析看机电设备安全运行问题. 见: 第十八次中国水电设备学术讨论会 论文集. 北京: 中国水利水电出版社, 2011. 329-336

7 伏安. 石漫滩、板桥水库的设计洪水问题. 中国水利, 2005, 16: 39-41

8 李君纯. 青海沟后水库溃坝原因分析. 岩土工程学报, 1994, 16: 1-14

9 顾冲时, 苏怀智, 刘何稚. 大坝服役风险分析与管理研究述评. 水利学报, 2018, 49: 26-35

10 王昭升, 吕金宝, 盛金保, 等. 水库大坝风险管理探索与思考. 中国水利, 2013, 8: 52-54

11 张建云, 杨正华, 蒋金平, 等. 水库大坝病险和溃坝研究与警示. 北京: 科学出版社, 2014

12 赵雪莹, 王昭升, 盛金保, 等. 小型水库溃坝初步统计分析与后果分类研究. 中国水利, 2014, 10: 33-35

13 彭雪辉, 盛金保, 李雷, 等. 中国水库大坝风险评价与决策研究. 水利水运工程学报, 2014, 3: 49-54

14 张建云, 盛金保, 蔡跃波, 等. 水库大坝安全保障关键技术. 水利水电技术, 2015, 46: 1-10

15 751

16 Zhong Q, Wu W, Chen S, et al. Comparison of simplified physically based dam breach models. Nat Hazards, 2016, 84: 1385-1418

17 Huang D, Yu Z, Li Y, et al. Calculation method and application of loss of life caused by dam break in China. Nat Hazards, 2017, 85: 39-57

18 王瑶, 万玉秋, 钱新, 等. 居民风险承受能力评价模型及实证分析. 环境科学与技术, 2009, 32: 185-189

19 于海欢, 万玉秋, 钱新, 等. 水库下游居民风险承受能力地域差异研究. 水利水电技术, 2009, 40: 105-108

20 Li J, Chen J Y, Xu Q. The assessment model about the disaster-bearing capacity of city's lifeline after dam-break. In: International Conference on Management \& Service Science. Wuhan, 2009. 1-4

21 于海欢, 万玉秋, 钱新, 等. 水库下游居民风险承受能力模糊综合评价. 中国农村水利水电, 2009, 2: 109-112

22 彭雪辉, 蔡跃波, 盛金保, 等. 中国水库大坝风险标准研究. 北京: 中国水利水电出版社, 2015

程翠云, 钱新, 万玉秋, 等. 水库大坝突发事件应急预案可行性评价方法初探. 水利水运工程学报, 2009, 1: 71-75

程翠云, 钱新, 杨珁, 等. 溃坝应急预案有效性评价. 岩土工程学报, 2008, 30: 1729-1733

SLZ720-2015水库大坝安全管理应急预案编制导则. 北京: 中国水利水电出版社, 2015

SL605-2013水库降等与报废标准. 北京: 水利水电出版社, 2013

顾冲时, 苏怀智, 刘何稚. 大坝服役风险分析与管理研究述评. 水利学报, 2018, 9: 26-35

29 李雷, 王仁钟, 盛金保, 等. 大坝风险评价与风险管理. 北京: 中国水利水电出版社, 2006

傅忠友, 张士辰. 基于工程实例的重力坝溃决模式和溃决路径分析. 水利水电技术, 2010, 41: 57-60

Aslett L J M, Nagapetyan T, Vollmer S J. Multilevel Monte Carlo for reliability theory. Reliability Eng Syst Saf, 2017, 165: 188-196

Kumar R,

34 吴世伟. 结构可靠度分析. 南京: 河海大学出版社, 2002

王晓航, 盛金保, 张行南, 等. 基于GIS技术的溃坝生命损失预警综合评价模型研究. 水力发电学报, 2011, 30: 73-78

Xu F, Yang X, Zhou J. Dam-break flood risk assessment and mitigation measures for the Hongshiyan landslide-dammed lake triggered by the 2014 Ludian earthquake. Geomatics Nat Hazards Risk, 2017, 8: 803-821

37 Fread D L. BREACH: An erosion model for earth dam failures. NOAA Technical Report, 1988

38 陈生水. 土石坝溃决机理与溃坝过程模拟. 北京: 中国水利水电出版社, 2012

39 Thompson J R, Sørenson H R, Gavin H, et al. Application of the coupled MIKE SHE/MIKE 11 modelling system to a lowland wet grassland in 
southeast England. J Hydrol, 2004, 293: 151-179

Chira I M, Chira R. The hydrological modeling of the Usturoi Valley-Using two modeling programs—WetSpa and HecRas. Carpath J Earth Environ Sci, 2006, 1: 53-62

41 Lee J Y, Park D H, Kim S J, et al. Estimation of break outflow from the Goeyeon Reservoir using DAMBRK model. J Korean Soc Civil Engineers, 2017, 37: 459-466

42 Wang S J, Li S Y, Zhou X B. FREAD's dam-break system-based back analysis on failure process of landslide dam. Water Resour Hydropower Eng, 2017, 48: 148-154

43 Zhang J Y, Li Y, Xuan G X, et al. Overtopping breaching of cohesive homogeneous earth dam with different cohesive strength. Sci China Ser ETech Sci, 2009, 52: 3024-3029

44 李云, 李君. 溃坝模型试验研究综述. 水科学进展, 2009, 20: 304-310

Liu L, Chang F X, Xiao C W, et al. Research progress on dam-break flood. J Yangtze River Sci Res Inst, 2016, 33: 29-35

李云, 祝龙, 宣国祥, 等. 土石坝漫顶溃决时间预测分析. 水力发电学报, 2013, 32: 174-178

Dam Safety Guidelines. Canadian Dam Association, 1999

Deniel D B, Alessandro P, Salman M A S. Regulatory frameworks for dam safety. The World Bank, 2002

Guidelines on Risk Assessment. Australian National Committee on Large Dams, 1994

Brown C A, Graham W J. Assessing the threat to life from dam failure. J Am Water Res Assoc, 1988, 24: 1303-1309

Maged A, Davis S B, Duane M M. GIS model for estimating dam failure life loss. Risk-Based Decision Mak Water Resour, 2002, 1: 1-19

Maijala T, Sarkkila J, Honkakunnas T. RESCDAM project—Developing emergency action planning. In: ICOLD European Symposium on Dams in an European Context. Geiranger: A A Balkema Publishers, 2001. 237-244

Assaf H, Hartford D N D. Estimating dam breach flood survival probabilities. ANCOLD Bull, 2003, 107: 23-42

盛金保, 彭雪辉. 中国水库大坝风险标准的研究. 见: 中国水利学会首届青年科技论坛论文集. 北京: 中国水利水电出版社, 2003. 476-480

李雷, 王仁钟, 盛金保. 溃坝后果严重程度评价模型研究. 安全与环境学报, 2006, 2: 1-4

孙玮玮. 溃坝后果综合评价方法及其应用研究. 博士学位论文. 南京: 南京水利科学研究院, 2012.10-12

周克发, 李雷, 盛金保. 中国溃坝生命损失评价模型初步研究. 安全与环境学报, 2007, 6: 145-149

Li S, Niu Z, Liu X, et al. Analysis of influencing factors of dam-break flood routing. J China Three Gorges Univ, 2016, 38: 1-5

王仁钟, 李雷, 盛金保. 病险水库判别标准体系研究. 水利水电科技进展, 2005, 25: 5-8

周克发, 彭雪辉. 中国溃坝生命损失调研报告. 技术报告. 南京: 南京水利科学研究院, 2009

Wang C, Zhang S, Tan Y, et al. Life loss estimation based on dam-break flood uncertainties and lack of information in mountainous regions of Western China. Trans Tianjin Univ, 2017, 23: 1-10

Peng M, Zhang L M. Analysis of human risks due to dam-break floods-Part 1: A new model based on Bayesian networks. Nat Hazards, 2012, 64: 903-933

盛金保, 赫健, 王昭升. 基于风险的病险水库除险决策技术. 水利水电科技进展, 2008, 28: 25-29

Li D D, Zhang S C, Cai Q, et al. Human reliability calculation method in dam risk analysis. Rev Facult Ingen, 2017, 32: 61-69

周兴波, 陈祖显, 黄跃飞, 等. 特高坝及梯级水库群设计安全标准研究III: 梯级土石坝连溃风险分析. 水利学报, 2015, 46: 765-772

郭新蕾, 周兴波, 夏庆福, 等. 梯级水库群控制梯级极端工况泄洪安全分析. 水利学报, 2017, 48: 1157-1166

周建平, 王浩, 陈祖煜, 等. 特高坝及其梯级水库群设计安全标准研究 I : 理论基础和等级标准. 水利学报, 2015, 46: 505-514

周建平, 周兴波, 杜效鹄, 等. 梯级水库群大坝风险防控设计研究. 水力发电学报, 2018, 37: 1-10

彭雪辉, 盛金保, 李雷, 等. 中国水库大坝风险标准制定研究. 水利水运工程学报, 2014, 4: 7-13

李雷, 蔡跃波, 盛金保. 中国大坝安全与风险管理的现状及其战略思考. 岩土工程学报, 2008, 30: 1581-1587

张士辰, 王晓航, 周克发. 溃坝条件下撤离路径优选程度的简易评价方法研究. 水利水电技术, 2013, 44: 41-44

Cheng C, Qian X, Zhang Y, et al. Estimation of the evacuation clearance time based on dam-break simulation of the Huaxi dam in Southwestern

China. Nat Hazards, 2011, 57: 227-243

向衍, 盛金保, 袁辉, 等. 中国水库大坝降等报废现状与退役评估研究. 中国科学: 技术科学, 2015, 45: 1304-1310

向衍, 盛金保, 杨孟, 等. 水库大坝退役拆除对生态环境影响研究. 岩土工程学报, 2008, 30: 1758-1764

赵雪莹, 水库报废决策及其生态环境影响评价方法和修复对策研究. 博士学位论文. 南京: 南京水利科学研究院, 2017

盛金保, 赵雪䒯, 王昭升. 水库报废生态环境影响及其修复. 水利水电技术, 2017, 48: 95-101 


\title{
Research progress and its practice of key techniques for dam risk assessment and management
}

\author{
SHENG JinBao ${ }^{1,2,3}$, LI DanDan ${ }^{1,2}$, CAI Qian ${ }^{1,2}$ \& PENG XueHui ${ }^{1,2}$ \\ ${ }^{1}$ Nanjing Hydraulic Research Institute, Nanjing 210029, China; \\ ${ }^{2}$ Dam Safety Management Center of the Ministry of Water Resources, Nanjing 210029, China; \\ ${ }^{3}$ State Key Laboratory of Hydrology-Water Resources and Hydraulic Engineering, Nanjing 210029, China
}

Dam risk is an objective existence. The assessment and management of dam risk are related to engineering safety and public safety. In this paper, an overview of the development of dam risk assessment and management techniques in China is made based on the statistical analysis of dam break probability. The connotation of dam risk management is defined. The key techniques of dam risk assessment and management are summarized including identification of dam break model and dam break path, calculation of the probability and consequences of dam break, human reliability, risk assessment and control of cascade reservoirs, dam risk criteria, risk decision, etc. The current application status of practical risk management techniques and tools in China dam safety management is analyzed including risk ranking and decision making, risk early-warning and emergency plan, dam demotion and retirement, annual report on dam safety and operation maintenance and monitoring manual. The future research direction of dam risk assessment and management techniques is prospected. It is hoped that further discussion on dam risk management among the whole industry could be carried out and the change from "engineering safety management" to "risk management" could be promoted as fast as possible in China.

\section{dam, human reliability, risk assessment, risk management}

doi: $10.1360 /$ N092018-00277 